\title{
CORRESPONDENCE
}

\section{FISHY VISION}

\section{To the Editors of The British Journal of Ophthalmologr.}

SiRS,-In reply to Sir James Barrett's letter in the March number of the Brit. Jl. of Oplithal., as I pointed out in my previous letter in the November number (1932), my observations on the refraction and accommodation are entirely confined to fresh-water fish. No generalised statement is of any use in regard to fish, as so much depends on their habitat. Taking the instance which Sir James quotes, namely, the periophthalmus or the little mud skipper, it is obvious that their eyes would not be of much service to them in the mud, but out of the mud, or when they climb the roots of the trees out of the water, their vision would be of service, and therefore

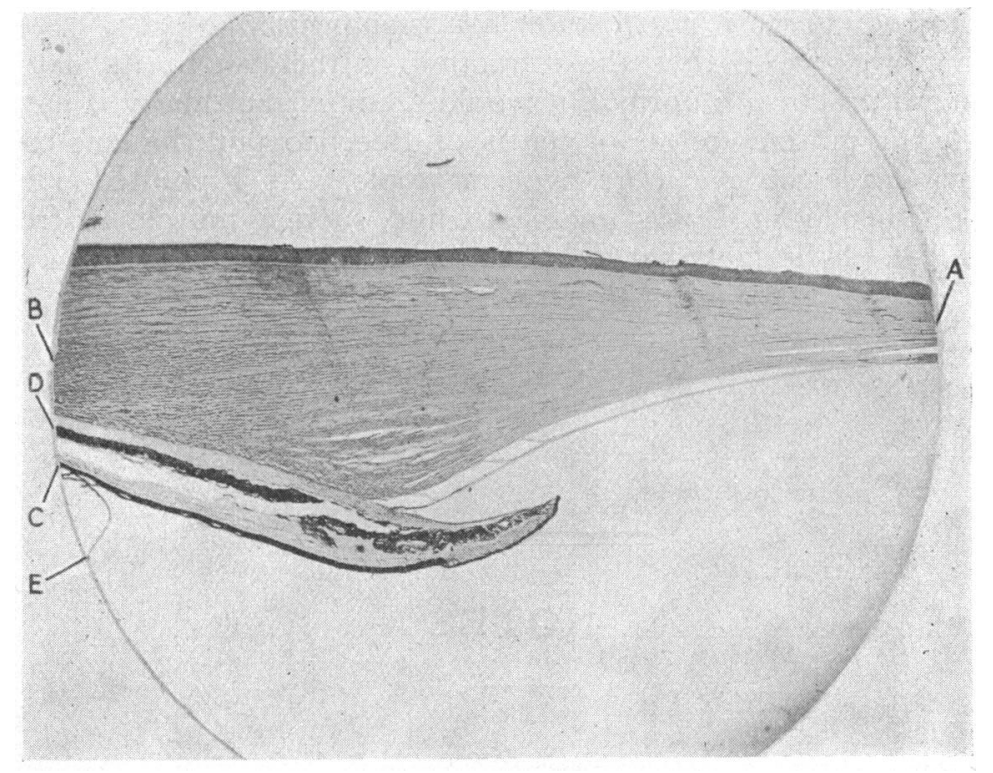

PIKE.

$(A)$ Cornea. (B) Sclera. Note the thin cornea with enormous thickening in the periphery. The increased curve of the inner surface of the cornea is also well seen with the slit-lamp. The thickening of the cornea helps to form a buttress support against the water pressure. (C) Iris. (D) Silvery layer of the iris which is continuous with the choroid. $(E)$ Ora serrata. There is no ciliary body. 
the refraction would require to be emmetropic out of the water. Still more interesting is the anableps tetrophthalmus which swims on the top of the water with half the eye out and half the eye in. I understand that in the top part of the eye the refraction is emmetropic or hypermetropic, while the portion of the eye which is in the water is myopic (out of the water).

My original observation was that in the water the refraction of fresh-water fish is either emmetropic or slightly hypermetropic. The fact that they are myopic out of the water has been confirmed over and over again. The reason of the alteration of refraction in the water is due to the abolition of the curve of the surface of the cornea. The curves of the cornea on the anterior and posterior surface differ considerably, the posterior curve being much greater than the anterior (see Fig). This no doubt increases the refractive power of the latter. It is brought about by buttress-like thickening of the margins of the cornea. At the limbus it is twice as thick as the central portion of the cornea. It not only increases the refraction of the inner surface, but helps to support the central portion of the cornea against the water pressure to which the unprotected cornea in fresh water fish is subject.

When we realise that the refraction of the fish in its natural element is practically normal, it would seem extraordinary if nature provided a muscle (retractor lentis of Beer) to pull the lens backwards to make the eye more hypermetropic. As I pointed out in my previous letter, I was unable to find such a muscle in freshwater fish. The fact that it is not present in these fish does not necessarily vitiate the researches of Beer.

Yours truly,

M. S. MAYOU.

NOTES

Death

Cambridge.

The Royal Society

WE are pleased to note the name of Dr. Gordon Holmes among the candidates recommended for election to the Fellowship of the Royal Society. 